\title{
Relapsing polychondritis with aortic involvement in fluorine-18 fluorodeoxyglucose positron emission tomography/computed tomography: A case report
}

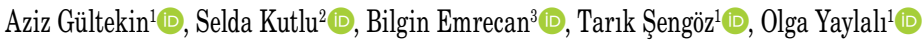 \\ ${ }^{1}$ Department of Nuclear Medicine, Pamukkale University Faculty of Medicine, Denizli, Turkey \\ ${ }^{2}$ Department of Clinical Microbiology and Infectious Diseases, Pamukkale University Faculty of Medicine, Denizli, Turkey \\ ${ }^{3}$ Department of Cardiovascular Surgery, Pamukkale University Faculty of Medicine, Denizli, Turkey
}

Received: August 04, 2020 Accepted: February 14, 2021 Published online: March 29, 2021

\begin{abstract}
An 83-year-old male patient presented with recurrent high fever. Vegetation was determined on transesophageal echocardiography, and antibiotic treatment was initiated for infective endocarditis. Despite medical treatment, progressive aortic insufficiency occurred and aortic valve replacement was performed. However, C-reactive protein (CRP) and fever did not decrease. During the clinical follow-up, pharyngolaryngeal pain and hoarseness, swelling, pain in the left auricle and nose increased. Fluorine-18 fluorodeoxyglucose positron emission tomography/computed tomography (18F-FDG PET/CT) scan was performed which revealed an increased 18F-FDG uptake in the ascending aorta, left ear, and nose. The patient was diagnosed with relapsing polychondritis (RPC). After the steroid and cyclophosphamide treatment, fever and CRP decreased dramatically. In conclusion, 18F-FDG PET/CT is an important imaging method for demonstrating RPC.
\end{abstract}

Keywords: Computed tomography, fluorodeoxyglucose F18, inflammatory aortitis, positron emission tomography, relapsing polychondritis.

Relapsing polychondritis (RPC) is a rare autoimmune, inflammatory disease which specifically affects the hyaline cartilage. ${ }^{[1,2]}$ The main challenge in the diagnosis of RPC is its rarity, lack of awareness, and a wide variety of symptoms. Therefore, many patients are diagnosed in advance stages. The most common symptoms are cough, fever, pain in the chest wall, sore throat, and arthralgia. Erythrocyte sedimentation rate, C-reactive protein (CRP), pulmonary function tests, and bronchoscopy are the most commonly used methods in the diagnosis. In recent years, fluorine- 18 fluorodeoxyglucose positron emission tomography/ computed tomography $\left({ }^{18} \mathrm{~F}-\mathrm{FDG} \mathrm{PET} / \mathrm{CT}\right)$ has been widely used as a powerful diagnostic tool. ${ }^{[3,4]}$ In this article, we report a rare case of RPC with ${ }^{18} \mathrm{~F}-\mathrm{FDG}$ $\mathrm{PET} / \mathrm{CT}$ findings.

\section{CASE REPORT}

An 83-year-old male patient presented with recurrent high fever and hospitalized. He had intermittent fever $\left(38.0\right.$ to $38.5^{\circ} \mathrm{C}$ ) every day. There was no bacterial growth in recurrent blood cultures. Serological and biochemical examination revealed fever of unknown origin. Brucella agglutination and human immunodeficiency virus (HIV) tests were all negative. The CRP value was $30.32 \mathrm{mg} / \mathrm{dL}$ (reference: $<0.5$ ) and white blood cell count was 13.02 $\mathrm{K} / \mu \mathrm{L}$ (reference: 4 to 10 ), which were all elevated. Vegetation and aortic valve insufficiency were determined on transesophageal echocardiography (TE). The patient was evaluated according to the Duke criteria. ${ }^{[5]}$ Possible endocarditis was diagnosed according to the Duke criteria and antibiotic treatment was initiated. However, the patient did not improve clinically. Moreover, aortic valve regurgitation progressed, and laboratory findings of the patient became more severe. A written informed consent was obtained from the patient and aortic valve replacement was performed. No vegetation was detected in the macroscopic examination of the aortic valve during the operation. Due to persistent fever and elevated liver enzymes, antibiotic therapy was

Corresponding author: Aziz Gültekin, MD. Pamukkale Üniversitesi Tıp Fakültesi, Nükleer Tıp Anabilim Dal, 20070 Kınıklı, Denizli, Türkiye.

Tel: +90 505 - 4969348 e-mail: agultekin@pau.edu.tr

Citation:

Gültekin A, Kutlu S, Emrecan B, Şengöz T, Yaylalı 0. Relapsing polychondritis with aortic involvement in fluorine-18 fluorodeoxyglucose positron emission tomography/ computed tomography: A case report. Cardiovasc Surg Int 2021;8(1):58-62. 


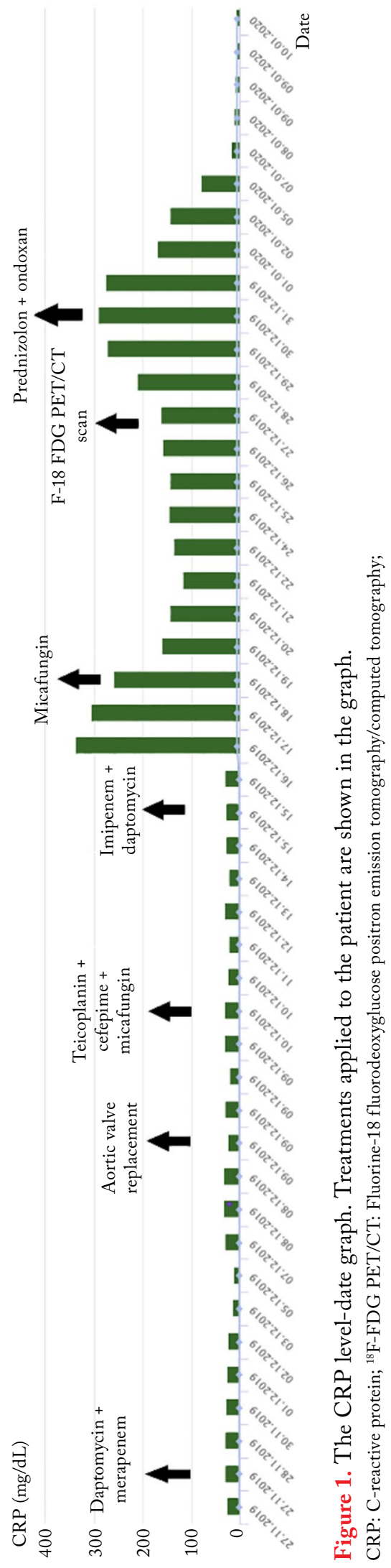

switched from teicoplanin and cefepime to imipenem and daptomycin (Figure 1). During follow-up, left ear pain, edema and erythema, nasal sensitivity, and redness of the nose and eye developed (Figure 2). Due to new-onset clinical findings, postoperative persistent fever, and elevated CRP levels, ${ }^{18} \mathrm{~F}-\mathrm{FDG}$ PET/CT scan was performed after the two weeks of surgery. The increased ${ }^{18} \mathrm{~F}-\mathrm{FDG}$ uptake was observed in the left ear, nose, eustachian tubes, and aorta compatible with inflammatory involvement of RPC (Figures 3 and 4). Severe ${ }^{18}$ F-FDG uptake around the
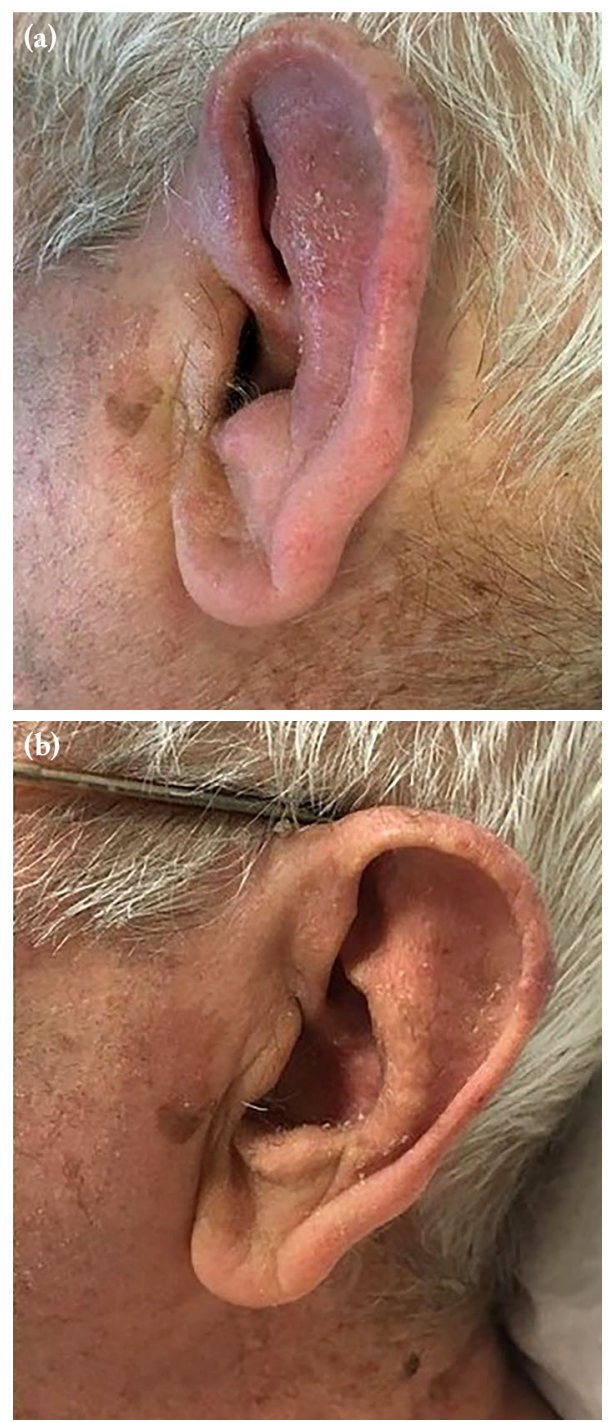

Figure 2. (a) During follow-up, edema and erythema developed in the left ear of the patient. (b) After treatment, the ear immediately returned to its normal appearance. 
(a)

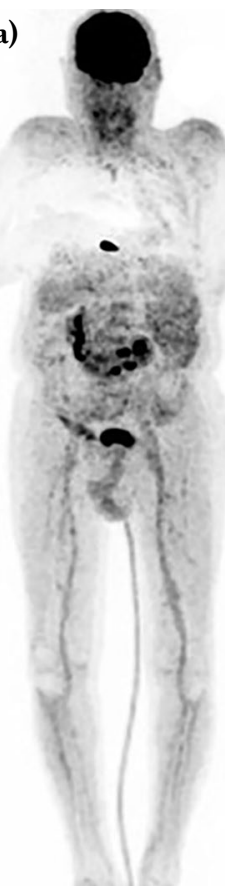

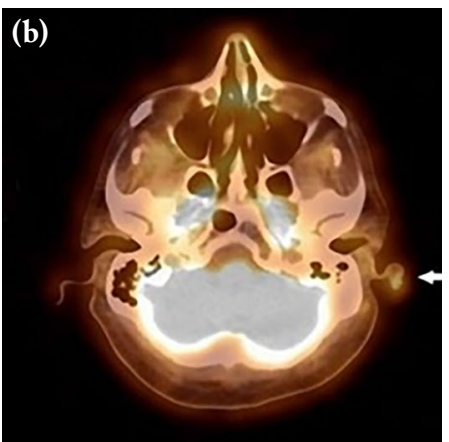

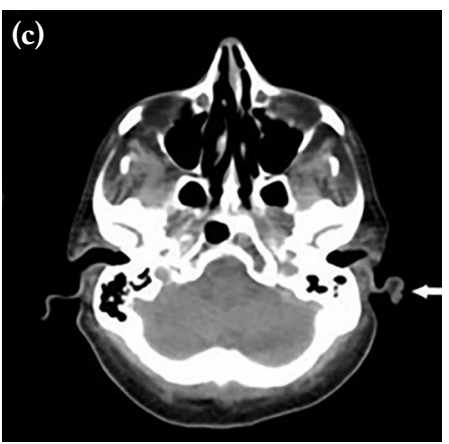

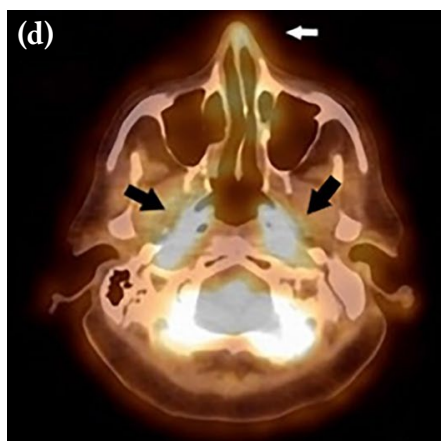

(e)

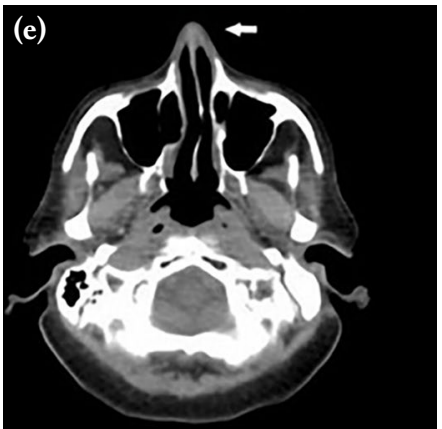

Figure 3. ${ }^{18} \mathrm{~F}-\mathrm{FDG}$ PET/CT showed increased ${ }^{18} \mathrm{~F}-\mathrm{FDG}$ uptake in the left auricle, nasal cartilage (b, d, white arrows) and bilateral eustachian tube (d, black arrow). The $\mathrm{SUV}_{\max }$ of the left ear was $2.87\left(\mathrm{SUV}_{\max }\right.$ of the right ear was 0.97) and the $\mathrm{SUV}_{\max }$ of the nose was 2.97. CT images showed thickening of the left auricle and nasal cartilage (c, e, white arrows).

18F-FDG PET/CT: Fluorine-18 fluorodeoxyglucose positron emission tomography/computed tomography; $\mathrm{SUV}_{\max }$ : Maximum standardized uptake value.
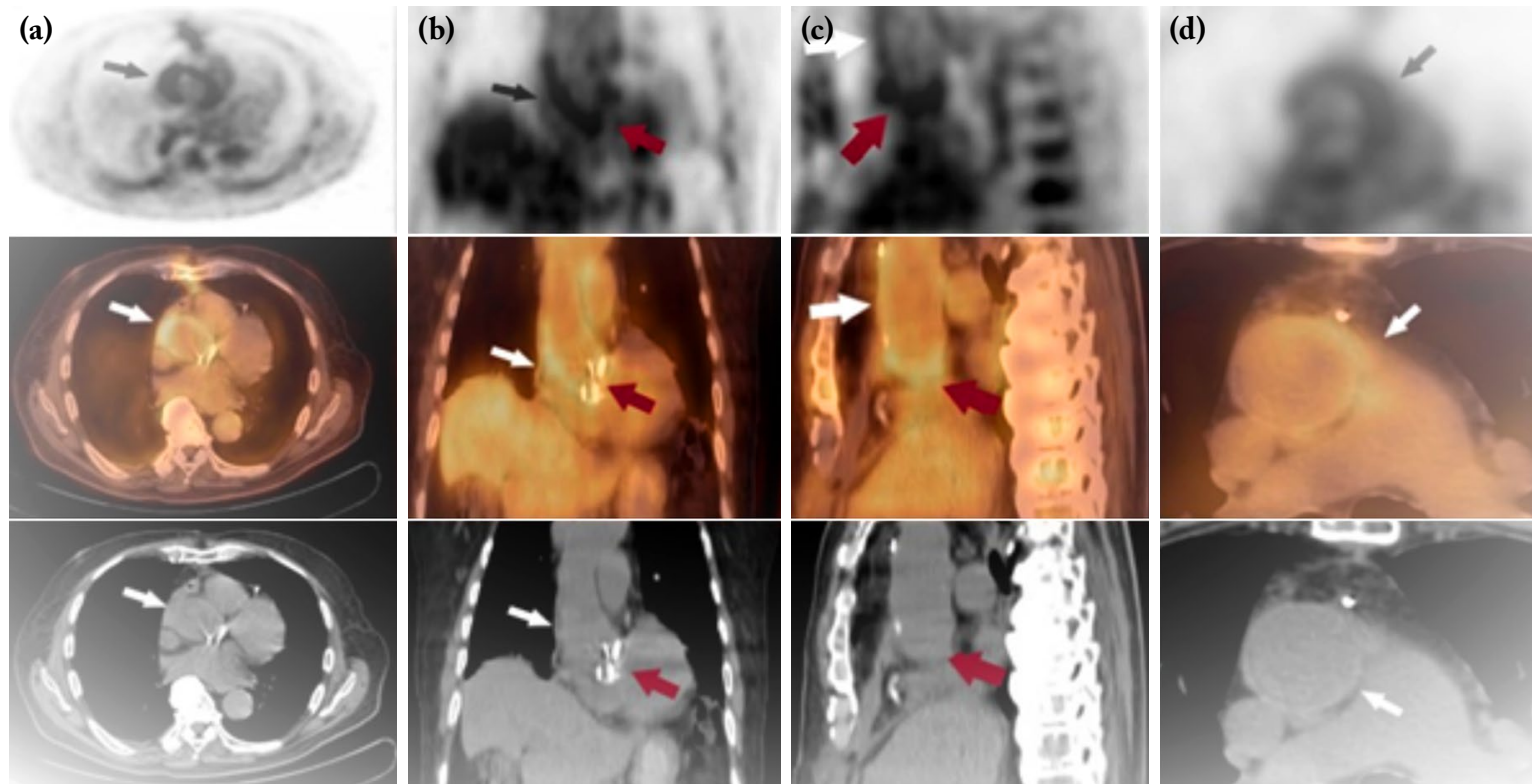

Figure 4. ${ }^{18} \mathrm{~F}-\mathrm{FDG}$ PET/CT scan showed wall thickening and increased ${ }^{18} \mathrm{~F}-\mathrm{FDG}$ uptake in the ascending aortic wall (SUV $\mathrm{max}_{\max }$ : 3.91). (a-d, black and white arrows). The FDG uptake around the operating materials was compatible with inflammation secondary to the operation. (b, c, red arrows).

${ }^{18}$ F-FDG PET/CT: Fluorine-18 fluorodeoxyglucose positron emission tomography/computed tomography; SUV max: Maximum standardized uptake value. 
aortic valve was interpreted as secondary inflammation related to surgery. A moderate ${ }^{18} \mathrm{~F}-\mathrm{FDG}$ uptake along with the thickening of ascending aortic wall was evaluated as the aortic involvement of RPC. Due to ${ }^{18} \mathrm{~F}-\mathrm{FDG}$ uptake in various cartilage tissues, RPC was considered. Steroid and cyclophosphamide treatment was initiated immediately. All of the clinical findings including fever disappeared and serum CRP returned to the normal levels.

\section{DISCUSSION}

The most common causes of fever of unknown origin are infections, neoplasms, and non-infectious inflammatory diseases. In this disease group, an individualized diagnosis algorithm is applied after a detailed patient history and physical examination. In our case, comprehensive clinical, biochemical, and microbiological examinations were performed initially to determine the etiology of fever. Intensive antibiotic therapy and aortic valve replacement were performed due to the diagnosis of infective endocarditis as evidenced by TE. Fever did not decrease after the operation and new clinical findings emerged. The ${ }^{18} \mathrm{~F}-\mathrm{FDG}$ PET/CT was performed which revealed inflammatory aortitis and polychondritis findings.

In the literature, there are some data indicating that immunological diseases are triggered, particularly after heart valve replacement. ${ }^{[6,7]}$ Of note, during the operation, insertion of a rigid prosthesis to the fragile position may cause latent inflammation and stimulate immunological reactions. ${ }^{[7]}$ Relapsing polychondritis is a systemic autoimmune disease characterized by progressive inflammation of hyaline cartilages (ear, nose, peripheral joints, and larynx/ trachea/bronchial tree) and proteoglycan-rich structures (eye, inner ear, heart, blood vessels, and kidneys). ${ }^{[1,2]}$ It affects most commonly the nose (90\%), ears (54 to $70 \%),{ }^{[8]}$ larynx and tracheobronchial tree (11 to 69\%), joints (18 to 81\%), and cardiovascular system (3 to 27\%). ${ }^{[9]}$ The disease usually follows a relapsing-remitting course. However, the destruction of the tracheobronchial cartilage may be complicated by infections. It can cause serious illnesses and even death. There may be an increase in the anti-collagen type II and anti-Matrilin-1 antibody. Computed tomography may be useful in diagnosis. In recent years, the ${ }^{18} \mathrm{~F}$-FDG PET/CT has been increasingly used for diagnostic purposes ${ }^{[3,4,8]}$ and follow-up ${ }^{[4]}$ of RPC. This tool is also useful to localize the biopsy site. ${ }^{[3]}$ The FDG is a radiopharmaceutical that accumulates in cancer tissues due to increased glucose utilization in neoplastic cells. However, the increase in glucose metabolism is not only specific for cancer, but also occurs in inflamed tissues. Respiratory system is affected in approximately $50 \%$ of RPC patients. Mortality and morbidity are usually associated with respiratory tree involvement. ${ }^{[10]}$ Cardiovascular complications are the second leading cause of mortality and morbidity in RPC, accounting for about one-third of patients. The rate of aortitis is $6.5 \% \cdot{ }^{[11]}$ Relapsing polychondritis is rare and, therefore, it is often overlooked in the differential diagnosis, leading to unnecessary treatment and interventions. Currently, there is no RPC-specific laboratory method or histopathological finding. Relapsing polychondritis is often diagnosed clinically. When ${ }^{18} \mathrm{~F}-\mathrm{FDG}$ PET/CT findings are evaluated combined with clinical findings, it is helpful to determine the extent of disease and severity of inflammation. In addition, evaluation of the response to treatment is also possible using this method.

In conclusion, open heart operations may trigger autoimmune diseases, such as RPC, or increase the severity of the existing condition. Polychondritis findings are typical on ${ }^{18} \mathrm{~F}-\mathrm{FDG} \mathrm{PET} / \mathrm{CT}$. The Increased uptake of ${ }^{18} \mathrm{~F}-\mathrm{FDG}$ in cartilages, with clinical suspicion, should suggest RPC.

\section{Declaration of conflicting interests}

The authors declared no conflicts of interest with respect to the authorship and/or publication of this article.

\section{Funding}

The authors received no financial support for the research and/or authorship of this article.

\section{REFERENCES}

1. Kubota K, Yamashita H, Mimori A. Clinical value of FDG-PET/CT for the evaluation of rheumatic diseases: Rheumatoid arthritis, polymyalgia rheumatica, and relapsing polychondritis. Semin Nucl Med 2017;47:408-24.

2. Bayer G, Diot E, Erra B. Utility of 18 F-FDG PET/CT in relapsing polychondritis. QJM 2015;108:339-40.

3. Yamashita H, Takahashi H, Kubota K, Ueda Y, Ozaki T, Yorifuji $\mathrm{H}$, et al. Utility of fluorodeoxyglucose positron emission tomography/computed tomography for early diagnosis and evaluation of disease activity of relapsing polychondritis: A case series and literature review. Rheumatology (Oxford) 2014;53:1482-90.

4. Sharma A, Kumar R, Mb A, Naidu GSRSNK, Sharma V, Sood A, et al. Fluorodeoxyglucose positron emission tomography/ computed tomography in the diagnosis, assessment of disease 
activity and therapeutic response in relapsing polychondritis. Rheumatology (Oxford) 2020;59:99-106.

5. Habib G, Lancellotti P, Antunes MJ, Bongiorni MG, Casalta JP, Del Zotti F, et al. 2015 ESC Guidelines for the management of infective endocarditis: The Task Force for the Management of Infective Endocarditis of the European Society of Cardiology (ESC). Endorsed by: European Association for Cardio-Thoracic Surgery (EACTS), the European Association of Nuclear Medicine (EANM). Eur Heart J 2015;36:3075-128.

6. McClendon CE, Leff RD, Clark EB. Postpericardiotomy syndrome. Drug Intell Clin Pharm 1986;20:20-3.

7. Noji S, Kitamura N, Yamaguchi A, Miki T, Shuntoh K. Relationship between postoperative prognosis and preoperative immunological factors in aortitis syndrome.
Nihon Kyobu Geka Gakkai Zasshi 1996 ;44:149-54.

8. Aslan H, Pınar E, Aladağ İ, İmre A, Çabuk E. Aurikuler tekrarlayıcı polikondrit: Olgu sunumu. Gaziosmanpaşa Üniversitesi Tip Fakültesi Dergisi 2015;7:76-83.

9. Lekpa FK, Chevalier X. Refractory relapsing polychondritis: challenges and solutions. Open Access Rheumatol 2018;10:1-11.

10. Wang J, Li S, Zeng Y, Chen P, Zhang N, Zhong N. ${ }^{18}$ F-FDG PET/CT is a valuable tool for relapsing polychondritis diagnose and therapeutic response monitoring. Ann Nucl Med 2014;28:276-84.

11. Elourimi G, Soussan M, Warzocha U, Bugaud H, Dhôte R, Abad S. Efficacy of tocilizumab highlighted by FDG-PET/ $\mathrm{CT}$ in a patient with relapsing polychondritis-associated aortitis. Rheumatol Int 2017;37:1931-5. 